\title{
Article \\ Effects of Post-Treatment to Improve the Surface Quality of 3D Printing Cement Mold Casting
}

\author{
Seung-Yeop Chun ${ }^{1,2}{ }^{\text {, Geumyeon Lee }}{ }^{1}$, Su-jin Kim ${ }^{1}$, Bora Jeong ${ }^{1}$, Jeehoon Shin ${ }^{3}{ }^{\circledR}$, Inkyung Cho ${ }^{1}$, \\ Hong-Dae Kim ${ }^{1}{ }^{\mathbb{C}}$, Heesoo Lee $^{2, *}$ and Taewook Kim ${ }^{1, * \mathbb{C}}$ \\ 1 Industrial Environment Green Deal Agency, Korea Institute of Industrial Technology, Ulsan 44413, Korea; \\ jsymen@kitech.re.kr (S.-Y.C.); kum0624@kitech.re.kr (G.L.); sujiny@kitech.re.kr (S.-j.K.); \\ bora1106@kitech.re.kr (B.J.); birdman98@kitech.re.kr (I.C.); hdkim@kitech.re.kr (H.-D.K.) \\ 2 Department of Material Science and Engineering, Pusan National University, Busan 46241, Korea \\ 3 Department of Materials Science and Engineering, Korea Advanced Institute of Science and Technology, \\ Daejeon 34141, Korea; jeehoonshin@naver.com \\ * Correspondence: heesoo@pusan.ac.kr (H.L.); taewook@kitech.re.kr (T.K.)
}

check for updates

Citation: Chun, S.-Y.; Lee, G.; Kim, S.-j.; Jeong, B.; Shin, J.; Cho, I.; Kim, H.-D.; Lee, H.; Kim, T. Effects of Post-Treatment to Improve the Surface Quality of 3D Printing Cement Mold Casting. Appl. Sci. 2021, 11, 11824. https://doi.org/10.3390/ app112411824

Academic Editor: César M. A.

Vasques

Received: 17 November 2021 Accepted: 8 December 2021 Published: 13 December 2021

Publisher's Note: MDPI stays neutral with regard to jurisdictional claims in published maps and institutional affiliations.

Copyright: (c) 2021 by the authors. Licensee MDPI, Basel, Switzerland. This article is an open access article distributed under the terms and conditions of the Creative Commons Attribution (CC BY) license (https:// creativecommons.org/licenses/by/ $4.0 /)$.

\begin{abstract}
Powder bed 3D printing can be applied to sandcasting mold manufacturing to ensure high quality and economy through process innovation. In this study, refractory alumina cement was used as an aqueous binder to ensure high-temperature thermal stability to minimize the addition of organic matter to reduce gas generation. In addition, spherical silica sand, the study material, was selected to a size of $30 \mu \mathrm{m}$ to improve the casting mold resolution. To improve the surface quality through the post-treatment process, we confirmed the change in the surface roughness of the mold depending on the surface treatment of colloidal silica and the presence or absence of heat treatment, and finally made the mold through actual casting. Changes in the surface roughness and flowability of the cast body after mold post-treatment were confirmed. For aluminum castings, the shrinkage rate and surface roughness were confirmed in a box-shaped mold via gravity casting, and the flowability of the molten metal in the mold was confirmed in a hand-shaped mold. There was a change in the roughness and porosity of the mold, owing to the post-treatment, and the influence of the surface roughness and flowability of the cast body during actual casting was confirmed.
\end{abstract}

Keywords: powder bed 3D printing; cement mold; green body; post-treatment; casting

\section{Introduction}

Metal casting has been steadily researched and developed in today's machinery and manufacturing fields as a method of pouring molten metal in which aluminum, cast iron, steel, special steel, etc. are melted into a mold to obtain the desired shape and characteristics [1]. The most traditional method, sand casting, has undergone many developments over a long history of 4000 years, and still occupies a large share in the modern casting market [2]. The powder bed method is a 3D printing technology that has received a great deal of attention in the sandcasting market. It is easy to apply to sand casting. Moreover, products applied to existing organic binders, inorganic binders, and cement binders have been developed. It is also notable in the casting market because mold making for large products is simply possible in an automatic process [3].

The current casting sand is specialized for large castings, which has an economic advantage, such as for marine engine parts. Accordingly, processing and storage costs are incurred, which makes the process inefficient and not economical $[3,4]$. In particular, it is difficult to supplement and apply the product because it is difficult to make a prototype. Even after casting, several post-processing processes are required to improve product quality; therefore, it takes a long time to secure the actual product [5]. On the other hand, if the powder bed method 3D printing process is applied, it is possible to produce an output, as well as complement the drawings that have been converted into data by omitting the 
wooden mold and mold production simultaneously, which enhances the prototype production process. Not only shortening, but also improving the surface roughness simplifies the post-casting post-treatment process [3]. In addition, through process automation, it is possible to secure uniform products and cast complex shapes that have not been applied to existing products $[3,6]$. This is an advantage that high-quality castings offer (can be secured in a single process), and it can also be economical not only for large castings but also for the high-quality and high-value-added casting industry [3].

ExOne and VoxelJet, the current leaders in the 3D printing casting market, prefer to use organic binders in the sand used for existing castings [6]. However, similar to the phenolic and furan binders used mainly in traditional sand casting, environmental pollution problems such as the generation of toxic gases occur [3]. Inorganic binders, such as cement and water glass, are essential to reduce the potential carbon footprint by reducing the gas evolution process [7]. The use of water glass, which is an inorganic binder, as an alternative, has the advantage of minimizing gas generation, but due to the difficulty in ensuring air permeability and the problem of recycling after use, product development is limited. On the other hand, cement, which is an aqueous binder, has attracted attention as a substitute for organic and inorganic binders, by minimizing the generation of organic gas, and refractory cement can minimize thermochemical reactivity to improve casting quality and ensure economic efficiency [8]. The cement powder as a porous binder offers significant advantages, such as easy integration of core and gating systems in the production of parts with complex internal geometries, as they do not interfere with rheological design elements without a vent structure [8]. In addition, the cement-bonded molded core of appropriate strength enables the design of complex shapes in the CPC aluminum process with an easy de-powdering function [9].

In this study, alumina cement, which is a high-temperature casting refractory cement, was used as a binder to select refractory spherical sand to produce 3D printing powder, and a mold was produced through a powder bed 3D printing process. After utilizing colloidal silica impregnation on the surface of the manufactured mold, we attempted to present a quality improvement measure by considering the change in the characteristics of the cast as the change in the characteristics of the mold, according to the process, by mixing.

\section{Method and Experiments}

\subsection{Powder Preparing and Powder Bed 3D Printing}

The 3D printing powder was prepared by mixing $30 \mu \mathrm{m}$ particle size spherical refractory silica (Fused silica, DIGHEN Composite Material Technology Co., Donghai, China) and 4000 mesh (4 $\mu \mathrm{m}$ particle size) sieve-filtered alumina cement (HF80N, Union Cement, Seoul, Korea) with a ball mill for $2 \mathrm{~h}$. Powder bed 3D printers (Freeforms-T150, SFS, Seoul, Korea) are $290 \times 210 \times 250 \mathrm{~mm}$ in size, with a $50 \mathrm{~mm}$ diameter antioxidant coated steel roller for transferring the powder via rotation from a powder supply bed, and stacking powder that is used for the green body and mold samples. The detailed process of laminating is to raise the feeding bed by $250 \mu \mathrm{m}$, transfer the powder with a roller, and form a layer filled with the powder that is transferred to the powder bed lowered by $100 \mu \mathrm{m}$. At the same time, the printheads (HP11, HP, USA) inject the executor (2-polypyrroledon $2 \%$ aqueous solution), according to the drawings present in the software. The injection amount was set to $50 \%$ for the activator/powder volume saturation level at the end of $2 \mathrm{~mm}$ of the printed surface, and $30 \%$ for the inside. Subsequently, the same process was repeated to complete the final lamination process. After drying for $1 \mathrm{~h}$, the printed body was removed, and the remaining powder was shaken off for post-processing (Figure 1). The rotation speed of the recoating roller was $6 \mathrm{~mm} / \mathrm{s}$, and the $x$-axis feed speed was $200 \mathrm{~mm} / \mathrm{s}$. 


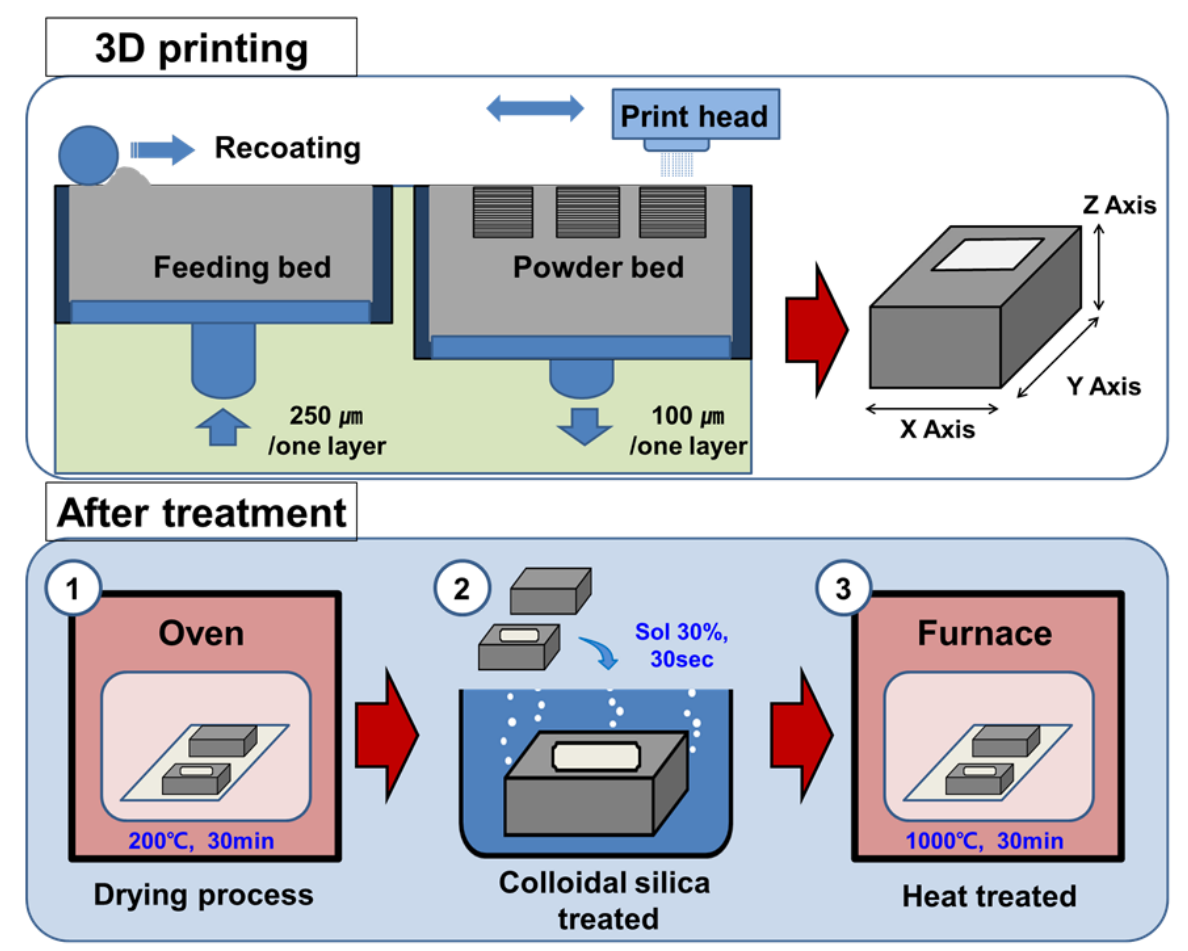

Figure 1. Mold production through powder bed 3D printing and post-treatment process of colloidal silica (1) organic matter and moisture removal of green body (G), (2) colloidal silica treatment (GC) (3) heat treatment $(\mathrm{GCH})$.

\subsection{Post-Processing}

As shown in Figure 1, the printed green body, from which the unbound powder on the surface was completely removed, was dried of the remaining water ( $\mathrm{G}$ sample) in an oven at $200{ }^{\circ} \mathrm{C}$ for $30 \mathrm{~min}$. After drying in an oven, green body surface was impregnated with $30 \%$ ethanol colloidal silica (Optisol-LSE330N, Lenko, Seoul, Korea) for $30 \mathrm{~s}$ (GC sample) and the sample heated at $1000^{\circ} \mathrm{C}$ for $30 \mathrm{~min}$ (GCH sample) immediately after impregnation with colloidal silica was finally obtained. A cylindrical molded body with a diameter of $10 \mathrm{~mm}$ and a height of $10 \mathrm{~mm}$ was used to measure the uniaxial compressive strength, and a $10 \times 10 \times 10 \mathrm{~mm}$ cube molded body for checking dimensional accuracy and surface roughness were produced as an output (Figure 2a). Twelve samples were selected and used for all measurements by unifying them (Figure $2 b$ ). For the post-treatment process, 12 samples were processed at a time for each process (Figure 2c).
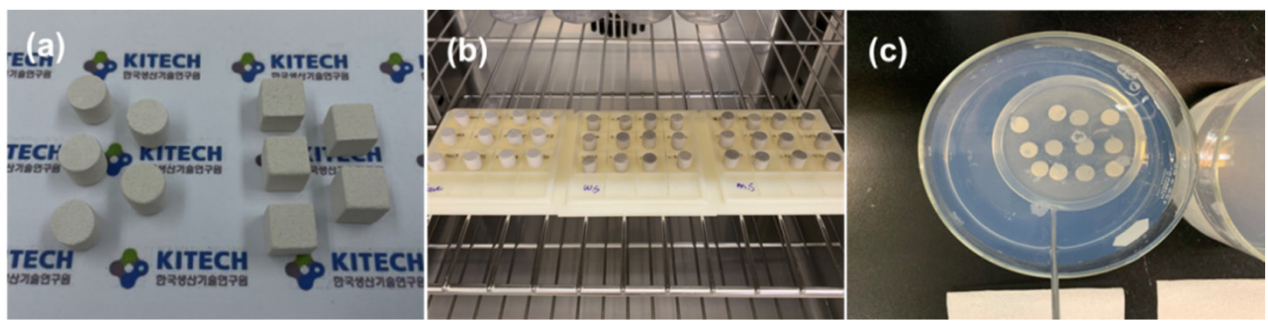

Figure 2. Powder bed 3D printing molded body (a) cylindrical molded body for strength confirmation and dice-shaped molded body for checking surface resolution and dimensional change (b) 12 samples for each condition for sample basic property evaluation (c) colloidal silica impregnation process.

\subsection{Casting Mold and Aluminum Casting}

To confirm the casting ability of the molded product, a box-shaped mold was produced in which the internal space was the same at $40 \mathrm{~mm} \times 40 \mathrm{~mm} \times 20 \mathrm{~mm}$, but the thickness was changed by 5,10 , and $15 \mathrm{~mm}$. The molds with the top open have an internal volume 
of $32 \mathrm{~mL}$ with a square bottom, and the outer wall has a uniform thickness. In addition, a hand-shaped mold was prepared to check the flowability of the casting. The hand-shaped mold was a $40 \mathrm{~mm} \times 60 \mathrm{~mm} \times 40 \mathrm{~mm}$ rectangular frame, and the ways were connected so that the molten metal could flow. All the ways were the same length at $50 \mathrm{~mm}$, but the widths were varied 3, 6,9 and $12 \mathrm{~mm}$. A mold with an inner wall and an outer wall thickness of $10 \mathrm{~mm}$ was manufactured.

AlSi9Cu3 used as a casting was melted at $700{ }^{\circ} \mathrm{C}$ in an electric furnace, and the schedule amount according to the internal volume of the designed mold was injected by the gravity casting method for the experiment. In addition, each mold sample was preheated at $200{ }^{\circ} \mathrm{C}$ for $2 \mathrm{~h}$ before the molten metal was injected.

\subsection{Characterization}

The uniaxial compressive strength was measured using a universal tester (MTS810, Material Test System Corp, Eden Prairie, MN, USA) with a cylindrical sample which had a diameter of $10 \mathrm{~mm}$ and a height of $10 \mathrm{~mm}$ at a fixed speed of $0.2 \mathrm{~mm} / \mathrm{min}$. The surface roughness was measured by contact-type roughness and expressed as the arithmetic mean roughness ( $\mathrm{Ra}$ ) value. $2 \mathrm{~mm}$ of random area excluding the edge of the sample surface, was measured 20 times for each. Porosity was measured by scanning the pore morphology using a microscale X-ray tomography platform (Xradia 510 Versa, Zeiss, Jena, Germany). To obtain sufficient transmission intensity (>5000 units), 75,000-100,000 projected images were taken with a spatial resolution of $20 \mu \mathrm{m}$ voxel size at $140 \mathrm{kV}$, and a $10 \mathrm{~W}$ atmospheric environment condition with a $1 \mathrm{~s}$ exposure of a $4 \mathrm{X}$ objective was set. The scanned data were analyzed and a program (Dragonfly, Object Research Systems, Montreal, QC, Canada) performed split/threshold to calculate the porosity of the binarized image. A field emission scanning electron microscope (Su8020, Hitachi, Tokyo, Japan) was used at 10-20 kV to confirm the surface shape of the sample. The crystal phase of the 3D printed template was profiled using X-ray diffraction (XRD, D/max Rigaku2200V/PC, Tokyo, Japan). Differential scanning calorimetry (DSC) analysis was performed by heating at $10^{\circ} \mathrm{C} / \mathrm{min}$ in an atmospheric environment using a thermal analyzer (STA449C/3/MFC/G, NETZSCH, Selb, Germany).

\section{Results and Discussion}

\subsection{Physical Property Evaluation}

The basic property of the molded body sample (G sample) after the powder bed 3D printing process was completed. The molded body sample was treated with colloidal silica (GC sample), followed by (GCH sample) subjecting it to heat treatment. Figure 3 shows the pressure compression strength of each sample with respect to the heating temperature. Each heating temperature was maintained for $30 \mathrm{~min}$ at $200^{\circ} \mathrm{C}$ up to $1200^{\circ} \mathrm{C}$, excluding $100{ }^{\circ} \mathrm{C}$, and the heating rate was $5{ }^{\circ} \mathrm{C} / \mathrm{min}$ in an atmospheric environment. To keep the sample conditions for each step the same, the time was maintained in an oven at $100{ }^{\circ} \mathrm{C}$. In the case of the $\mathrm{G}$ sample, in the heat treatment process at $200{ }^{\circ} \mathrm{C}$, the sample obtained immediately after printing had the highest strength. The strength decreased as the temperature increased and increased again after heat treatment at $800{ }^{\circ} \mathrm{C}$ or higher. The increase in strength during the $200^{\circ} \mathrm{C}$ heat treatment can be attributed to the increase in the role of the cement binder due to the evaporation of the remaining water, similar to the result of Salomão et al. [10]. The subsequent decrease in strength was due to the dehydration characteristics of alumina cement [9], and the increase in strength above $800{ }^{\circ} \mathrm{C}$ was confirmed in the complete dehydration reaction [11,12]. Therefore, the printed sample (G sample) was obtained by drying at $200^{\circ} \mathrm{C}$ for $30 \mathrm{~min}$. The strength of the GC sample increased to $6.3 \mathrm{MPa}$ at $4.4 \mathrm{MPa}$ at $100{ }^{\circ} \mathrm{C}$ with colloidal silica impregnation, and higher intensity than that of the G sample was confirmed in most sections except $200^{\circ} \mathrm{C}$. When heat treatment was performed at $1000{ }^{\circ} \mathrm{C}$ or higher, it appears that the strength of the colloidal silica was significantly higher than $12.4 \mathrm{MPa}$ due to the strengthening of the bonding force as a result of recrystallization [13-18]. The colloidal silica-treated sample 
shows the same tendency as after printing, but the ethanol-based colloidal silica solvent evaporates sufficiently at $100{ }^{\circ} \mathrm{C}$; thus, the same strength is expected to be displayed at $200{ }^{\circ} \mathrm{C}$. It was confirmed that the strength was higher at heat treatment temperatures higher than $200^{\circ} \mathrm{C}$ [18]. In the case of the $\mathrm{GCH}$ sample, the same strength as the G sample, which was heat treated at $1000{ }^{\circ} \mathrm{C}$, was shown because it had already been heat treated at $1000^{\circ} \mathrm{C}$.
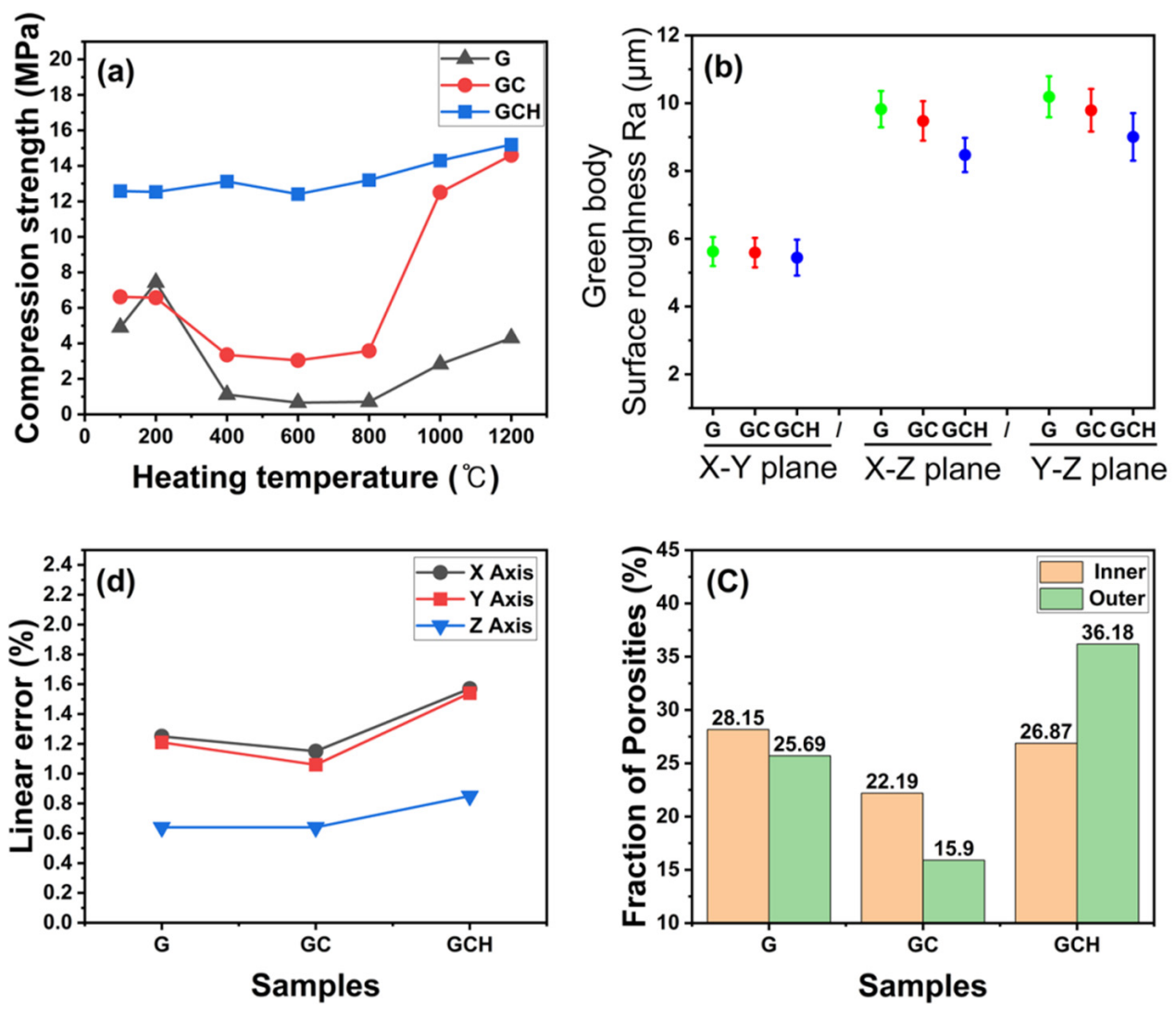

Figure 3. (a) Uniaxial compressive strength according to heat treatment temperature (b) $\mathrm{Ra}(\mu \mathrm{m})$ of $X Y, X Z, Y Z$ surfaces of the molded body by process (c) average porosity inside and outside the molded body $(\%)(\mathbf{d})$ dimensional error of molded object $x, y, z$ axis.

The amount of gas generated in the mold for each process was confirmed by the change in mass of the sample stored at $100{ }^{\circ} \mathrm{C}$ during heat treatment at $1000{ }^{\circ} \mathrm{C}$. The $\mathrm{G}$ sample showed a mass loss of $2.0 \pm 0.2 \%$, and the GC sample also showed a similar mass loss of $2.2 \pm 0.4 \%$. In addition, the GCH sample appeared to be almost unchanged at $1.0 \% \pm 0.3 \%$ (Table 1 ).

Table 1. Mold and casting body shrinkage rate (\%) for each process according to the thickness of the outer wall of the box mold.

\begin{tabular}{ccccc}
\hline \multirow{2}{*}{ Specimens } & Mass Loss Rate (\%) & \multicolumn{3}{c}{ Bottom Area Shrinkage (\%) } \\
\cline { 3 - 5 } & $\begin{array}{c}\mathbf{5} \mathbf{~ m m} \\
\text { Thickness }\end{array}$ & $\begin{array}{c}\mathbf{1 0} \mathbf{~ m m} \\
\text { Thickness }\end{array}$ & $\begin{array}{c}\mathbf{1 5} \mathbf{~ m m} \\
\text { Thickness }\end{array}$ \\
\hline $\begin{array}{c}\text { G } \\
\text { Cast body }\end{array}$ & $2.0 \pm 0.2$ & $1.2 \pm 0.3$ & $1.6 \pm 0.2$ & $2.4 \pm 0.3$ \\
$\begin{array}{c}\text { GC } \\
\text { cast body } \\
\begin{array}{c}\text { GCH } \\
\text { cast body }\end{array}\end{array}$ & $2.2 \pm 0.4$ & $1.5 \pm 0.2$ & $2.4 \pm 0.5$ & $4.4 \pm 0.5$ \\
\hline
\end{tabular}


Figure $2 \mathrm{~b}$ shows the surface election lacquer ware of the sample for each process in terms of Ra value, and each surface of the 3D-printed cube sample was measured. The printed floor surface (X-Y plane) has a relatively better surface roughness than the side surface, which is thought to be due to the role of the rollers in recoating and solidifying the printed surface [19]. Therefore, there was almost no change in the surface roughness due to the post-treatment process. On the other hand, in the case of the X-Z and Y-Z planes, the surface roughness after colloidal silica treatment was improved, which was better than that after heat treatment. Owing to the 3D printing characteristics, this affects the surface quality of the printed product displayed on the 3D printing process, where bending occurs owing to the stacking error of the side surface. Thus, research to improve the resolution of the side surface of the printed product is actively progressing [20]. This is the same as the result demonstrating that nano-colloidal silica plays a role in smoothing the lateral bending [21]. Figure $3 \mathrm{c}$ shows the porosities of the samples for each process. The porosity of the surface after printing was smaller than the porosity of the inside because the activator saturation level of the molded end and the inside was different as set by the 3D printer. In addition, the surface impregnation after treatment with colloidal silica resulted in a surface porosity of $15.9 \%$, and a decrease of nearly $10 \%$. After the heat treatment process, the porosity increased, and the internal porosity appeared to be less than the pre-treatment level of conventional colloidal silica. However, the surface porosity was $36.18 \%$, which is higher than the $25.69 \%$ of the G sample. Thus, an increase of more than $10 \%$ was seen. This is seen in the displayed changes as the heat treatment of colloidal silica promotes crystalline changes in the silica sand [18]. The thermal condensation of colloidal silica impregnated in the gaps between the aggregates increases the gap between the aggregates, which in turn results in an increase in the pores of the GCH sample [19].

Figure $3 \mathrm{~d}$ shows the dimensional changes in the molded product for each process. Set to $10 \mathrm{~mm}$ on the 3D printing drawing, the lengths of the $X_{-}, Y_{-}$, and $Z$-axes show a dimensional error of $2 \%$ or less in the sample for each process, and the $z$-axis error was relatively smaller than the $X$ and $Y$ axes. This is because when the $z$-axis activator in the print direction penetrates, it was absorbed by the pre-printed part in the downward direction and was printed relatively accurately at the intended print height, while the lateral spread appeared to be a result that was not effectively controlled [20,21].

To confirm the changes in the surface roughness and pore fraction of the molded product for each process, the SEM image (Figure 4), XRD crystal phase (Figure 5) analysis, and DSC (Figure 6) analyses were performed. The SEM image of the surface after printing (Figure 4) confirmed the bond between the sand and the cement binder; after treatment with colloidal silica, it was flattened by the nano-silica particles on the surface. Subsequent heat treatment supports an increase in the porosity of the surface when fine cracks occur in the treated portion of the colloidal silica [18]. In addition, after the treatment of colloidal silica, in order to confirm the change of the crystal phase due to heat treatment, the change of the XRD crystal after the heat treatment for $30 \mathrm{~min}$ at 700 and $1000{ }^{\circ} \mathrm{C}$ (Figure 5) was confirmed. When the silica sand was not treated with colloidal silica, the sample heattreated at $200{ }^{\circ} \mathrm{C}$ showed an image of the existing component, fused silica, which was found to be the same at 700 and $1000{ }^{\circ} \mathrm{C}$. On the other hand, in the silica sand treated with colloidal silica, cristobalite crystals were observed at $700{ }^{\circ} \mathrm{C}$, and the strength further increased at $1000^{\circ} \mathrm{C}$. To confirm the accurate phase change, the DSC thermal change curve was confirmed, as shown in Figure 6. The change in heat flow of the sample after printing is shown by a solid black line, and when colloidal silica is treated, the change in heat flow is indicated by a solid red line. After printing, the endothermic peak was confirmed at $1056{ }^{\circ} \mathrm{C}$ without a large heat flow change up to $800^{\circ} \mathrm{C}$. At this time, the formation of the cristobalite award can be inferred, and when colloidal silica is treated, the formation of the cristobalite award can be inferred at $675.7^{\circ} \mathrm{C}$. An endothermic peak is observed. Therefore, the presence or absence of the XRD phase change was confirmed at $700{ }^{\circ} \mathrm{C}$ or higher, as shown in Figure 5. 


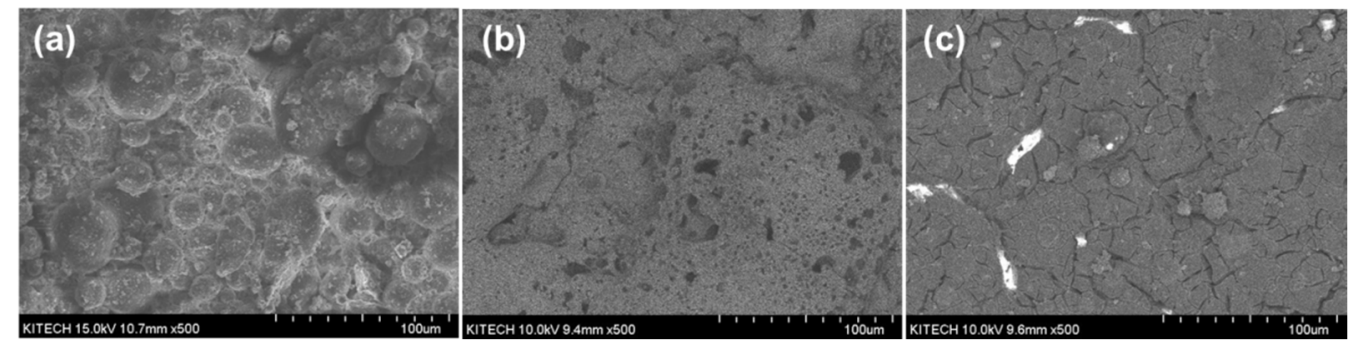

Figure 4. Surface SEM image of powder bed 3D printed molded body after (a) printing (G sample) (b) colloidal silica treatment (GC sample) (c) after final heat treatment (GCH sample).

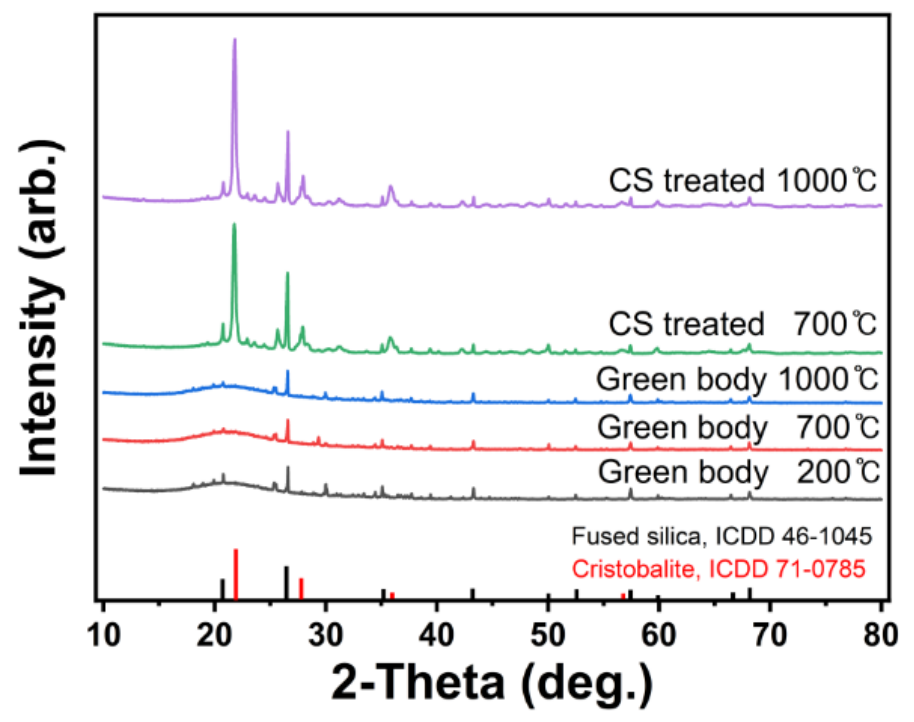

Figure 5. Confirmation of XRD peaks of samples after molding of powder bed 3D printed article and after heat treatment at 200,700 , and $1000{ }^{\circ} \mathrm{C}$ after treatment with colloidal silica.

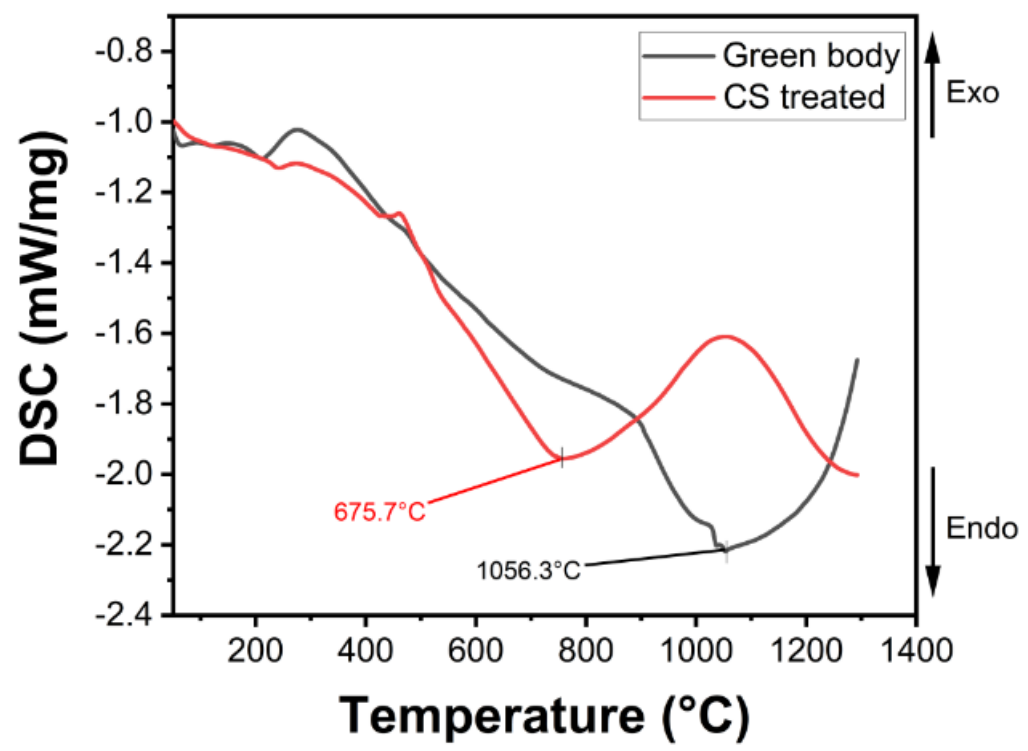

Figure 6. DSC heat flow measurement after printing (G sample) and colloidal silica treatment (GC sample) of a powder bed 3D printed molded body.

\subsection{Casting Resolution}

The molten aluminum was prepared in $32 \mathrm{~mL}$ to match the internal space of the mold, and casting was manufactured using the gravity casting method at a temperature of 
$700{ }^{\circ} \mathrm{C}$. Casting was carried out 45 times in total by preparing five molds for each process (Figure $7 \mathrm{a}$ ). Figure $7 \mathrm{~b}$ shows a fully formulated aluminum casting specimen after $10 \mathrm{~h}$ at room temperature after casting. For each specimen, it was confirmed that the upper part not in contact with the mold was bent owing to shrinkage, and the shrinkage rate of the inner bottom surface in contact with the surface of the mold was compared for accurate experiments (Table 1). Table 1 shows that the shrinkage after colloidal silica treatment (GC sample) was higher than that of the mold (G sample) after molding, which seems to be due to the decrease in porosity [22]. On the other hand, the change in shrinkage after heat treatment (GCH sample) appears to be noticeably reduced, probably due to an increase in porosity [23].
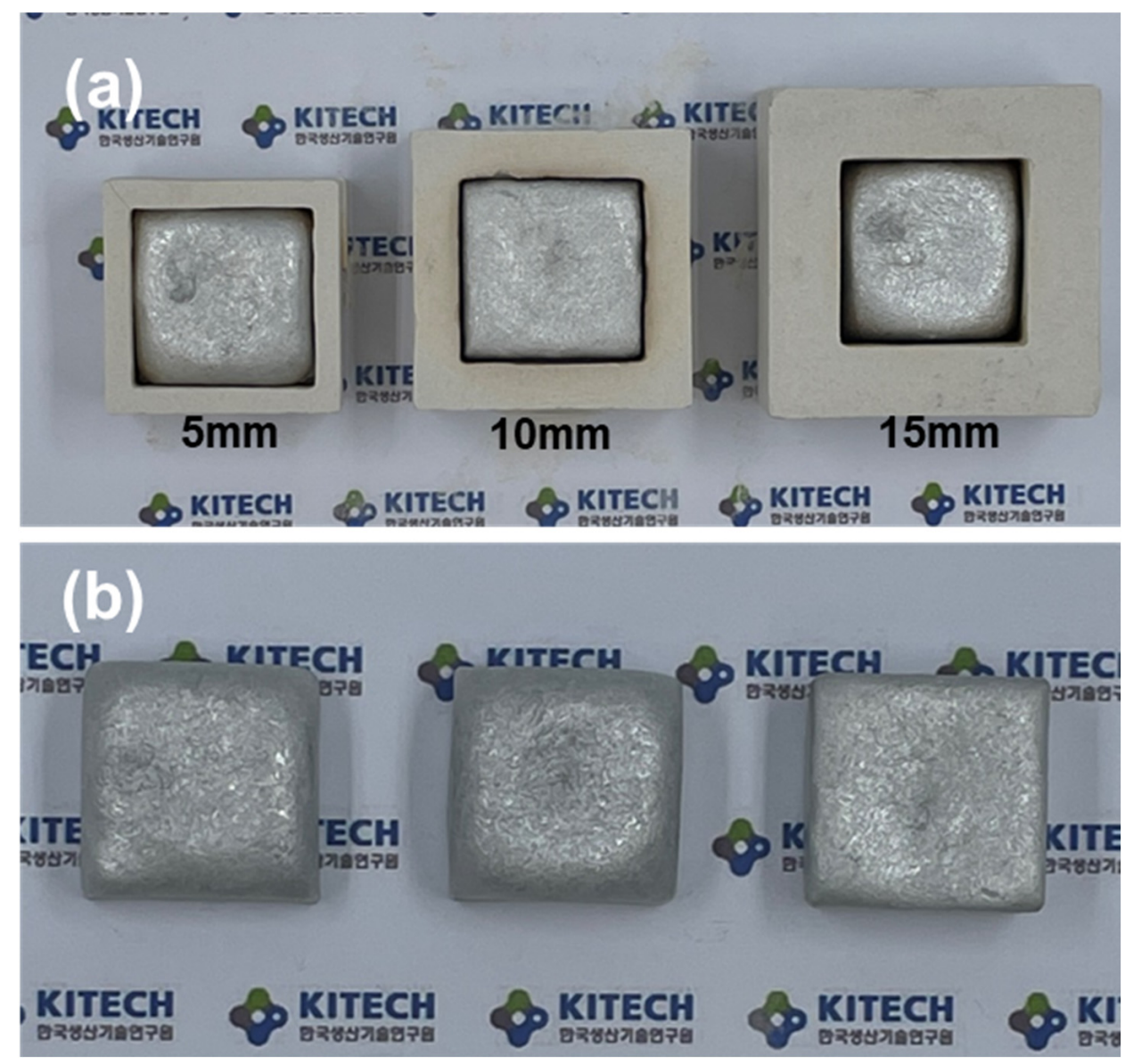

Figure 7. (a) The molten metal was poured into the mold and the casting and (b) specimens after casting aluminum with box mold thicknesses of 5, 10, and $15 \mathrm{~mm}$.

In addition, the shrinkage rate tends to increase as the thickness of the mold increases from $5 \mathrm{~mm}$ to $15 \mathrm{~mm}$, even if the porosity is different, further supporting the change in shrinkage due to the air permeability of the mold [23] Next, the Ra values of the inner surface $(X-Y, X-Z$, and $Y-Z$ plane) of the casting specimen in contact with the inside of the mold with a thickness of $10 \mathrm{~mm}$ were compared with Figure 8. The surface roughness of the post-molding mold ( $\mathrm{G}$ sample) casting specimen and that after colloidal silica treatment (GC sample) are displayed in the same manner. The surface roughness on the XY plane side, which is the laminated molding surface, appears to improve. This seems to be owing to the surface roughness of the mold. It also shows better surface roughness on the inner surface of the cast specimen after heat treatment (GCH sample). This is believed to be because the microcracks on the surface of the mold in Figure 4c do not impair the resolution of the surface of the casting, but rather, the surface roughness is improved by the surface of the mold flattened with colloidal silica and the increased permeability. 


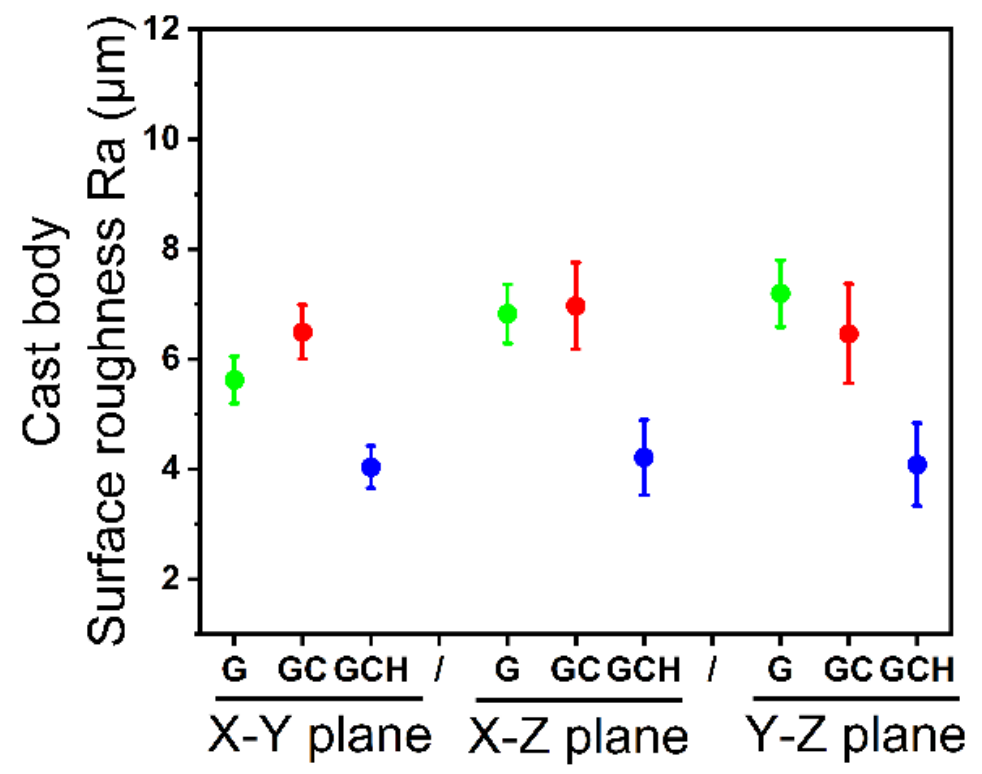

Figure 8. Surface roughness of X-Y, X-Z, Y-Z surfaces of a box-shaped $10 \mathrm{~mm}$ thick mold by process.

\subsection{Casting Flowability}

The molten aluminum was prepared in a mold in a volume of $100 \mathrm{~mL}$, and casting was performed using a gravity casting method at a temperature of $700{ }^{\circ} \mathrm{C}$. Casting was carried out 15 times in total by preparing five molds for each process (Figure 9a). The bottom surface of the specimen confirmed the flowability of the molten metal (Figure 9b). In Table 2, the comparison of the lengths of the casting results of the molds for each process flowing in the hand-shaped way was confirmed by the rice arrival length \%, in comparison to the total length of $50 \mathrm{~mm}$. There is a slight difference in the length flowing in the $12 \mathrm{~mm}$ width gap at the level of $1 \%$ to $3 \%$, but the difference is clearly classified in the width of $9 \mathrm{~mm}$ or less. After forming with a width of $3 \mathrm{~mm}$, it seems that the flowability clearly decreased after colloidal silica treatment (GC sample) from the template (G sample), showing that the impact of the improvement is insignificant. In addition, in the case of the casting specimen of the mold (GCH sample) that had undergone the heat treatment process, it was confirmed that the flowability was improved by nearly $20 \%$, along with the improvement in the surface roughness of the mold, as confirmed in Figure $3 c$. The increase in pore ratio in Figure 4 has a significant effect on the flowability of the casting.
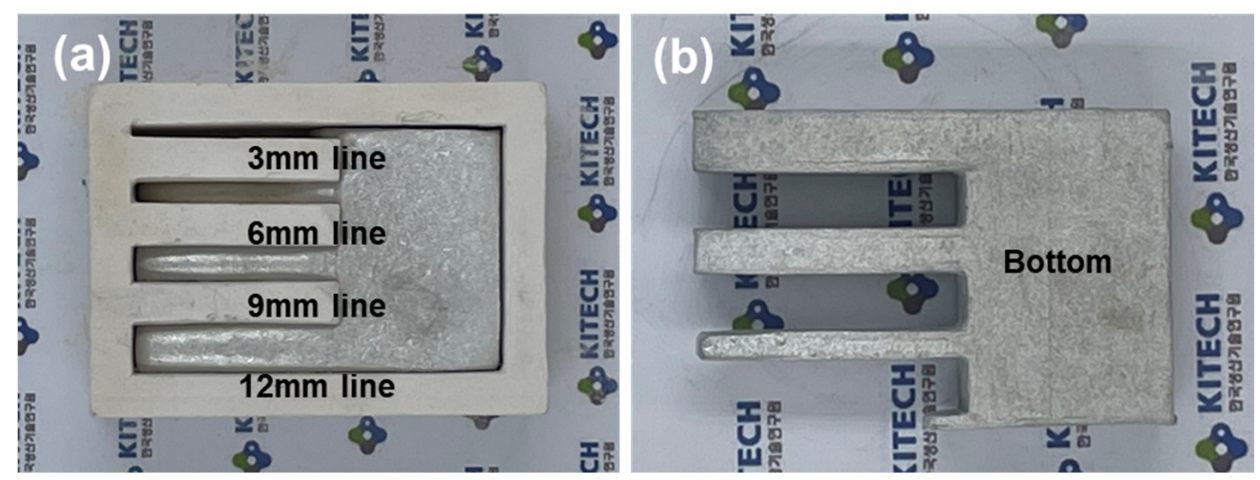

Figure 9. Hand-shaped mold for checking flowability by process (a) mold and casting with molten metal poured (b) bottom surface of hand-shaped aluminum casting. 
Table 2. Hand-shaped mold casting rice for each process according to the gap diameter of the mold (\%).

\begin{tabular}{ccccc}
\hline \multirow{2}{*}{ Specimens } & \multicolumn{4}{c}{ Linear Error (\%) } \\
\cline { 2 - 5 } & $\begin{array}{c}\mathbf{3} \mathbf{~ m m} \\
\text { Line }\end{array}$ & $\begin{array}{c}\mathbf{6} \mathbf{~ m m} \\
\text { Line }\end{array}$ & $\begin{array}{c}\mathbf{9} \mathbf{~ m m} \\
\text { Line }\end{array}$ & $\begin{array}{c}\mathbf{1 2} \mathbf{~ m m} \\
\text { Line }\end{array}$ \\
\hline $\begin{array}{c}\text { G } \\
\text { cast body } \\
\text { GC } \\
\text { cast body } \\
\text { GCH } \\
\text { cast body }\end{array}$ & $84 \pm 7.0$ & $5 \pm 0.8$ & $3 \pm 0.4$ & $2 \pm 0.2$ \\
\hline
\end{tabular}

\section{Conclusions}

Alumina cement, a high temperature cast refractory cement, was used as a binder, and a 4000 mesh $(4 \mu \mathrm{m})$ size that can be applied to $30 \mu \mathrm{m}$ spherical silica sand was selected. The casting sand made of cement mixed sand was manufactured as a mold through the powder bed 3D printing process to secure the surface resolution, and, at the same time, it was confirmed that the casting quality was improved by securing the gas permeability and surface smoothness of the molding sand. In addition, the casting quality was improved by supplementing the resolution after colloidal silica impregnation and improving the strength of the mold surface. For the final manufactured mold, it was confirmed whether the dimensional accuracy of the casting body and the resolution of the surface could be secured through aluminum casting.

In the casting, to check the surface smoothness of the mold, the depth of the casting was compared with the method of various thicknesses. In addition, the surface resolution and flow properties of aluminum casting were investigated to understand the influence of the increase in surface resolution and porosity. As a result, the surface resolution and flowability of the casting were improved by increasing the porosity rather than improving the surface resolution.

Therefore, this will be a more economical process if it can achieve higher porosity without a post-treatment process such as colloidal silica. It will be possible to take advantage of the detailed additive manufacture modeling of the $30 \mu \mathrm{m}$ aggregate size that can be applied to actual casting. This will require further optimization of the cement binder.

Author Contributions: Conceptualization, S.-Y.C.; methodology, G.L., S.j.K., B.J. and J.S.; validation, H.-D.K. and H.L.; formal analysis, T.K.; investigation, H.-D.K.; resources, H.-D.K. and I.C.; writingoriginal draft preparation, S.-Y.C.; writing—review and editing, S.-Y.C. and T.K.; visualization, G.L.; supervision, H.L.; project administration, H.-D.K.; funding acquisition, H.-D.K. All authors have read and agreed to the published version of the manuscript.

Funding: This work was supported by Korea Ministry of Trade Industry and Energy (Grant number: \#10067386) and Korea Ministry of Science and ICT (Grant number: EO200014).

Institutional Review Board Statement: Not applicable.

Informed Consent Statement: Not applicable.

Data Availability Statement: All data are presented in this article in the form of figures and tables.

Acknowledgments: We acknowledge the financial support from the Ministry of Trade, Industry and Energy, Korea (MOTIE, grant number: \#10067386) and the Ministry of Science and ICT, Korea (MSIT, grant number: EO200014).

Conflicts of Interest: The authors declare no conflict of interest. 


\section{References}

1. Pal, H.; Jit, N.; Tyagi, A.K.; Sidhu, S. Metal Casting-A General Review. Adv. Appl. Sci. Res. 2011, 2, 360-371.

2. Zheng, J.; Chen, A.; Zheng, W.; Zhou, X.; Bai, B.; Wu, J.; Ling, W.; Ma, H.; Wang, W. Effectiveness analysis of resources consumption, environmental impact and production efficiency in traditional manufacturing using new technologies: Case from sand casting. Energy Convers. Manag. 2020, 209, 112671. [CrossRef]

3. Yilmaz, O.; Anctil, A.; Karanfil, T. LCA as a decision support tool for evaluation of best available techniques (BATs) for cleaner production of iron casting. J. Clean. Prod. 2015, 105, 337-347. [CrossRef]

4. Hodder, K.J.; Chalaturnyk, R.J. Bridging additive manufacturing and sand casting: Utilizing foundry sand. Addit. Manuf. 2019, 28, 649-660. [CrossRef]

5. Sivarupan, T.; Balasubramani, N.; Saxena, P.; Nagarajan, D.; El Mansori, M.; Salonitis, K.; Jolly, M.; Dargusch, M.S. A review on the progress and challenges of binder jet 3D printing of sand moulds for advanced casting. Addit. Manuf. 2021, 40, 101889. [CrossRef]

6. Upadhyay, M.; Sivarupan, T.; El Mansori, M. 3D printing for rapid sand casting-A review. J. Manuf. Process. 2017, 29, 211-220. [CrossRef]

7. Wan, P.; Zhou, J.; Li, Y.; Yin, Y.; Huang, D.; Ji, X.; Shen, X. Experimental Study on Gas Evolution Process of Binders in Foundry Industry based on TG-MS. Procedia Manuf. 2019, 37, 311-318. [CrossRef]

8. Simonin, F.; Olagnon, C.; Maximilien, S.; Fantozzi, G.; Diaz, L.A.; Torrecillas, R. Thermomechanical behavior of high-alumina refractory castables with synthetic spinel additions. J. Am. Ceram. Soc. 2000, 83, 2481-2490. [CrossRef]

9. Liu, X.; Hao, Z.; Huang, M. Optimization of vacuum counter-pressure casting process for an aluminum alloy casing using numerical simulation and defect recognition techniques. Int. J. Adv. Manuf. Technol. 2020, 107, 2783-2795. [CrossRef]

10. Salomão, R.; Pandolfelli, V.C. The role of hydraulic binders on magnesia containing refractory castables: Calcium aluminate cement and hydratable alumina. Ceram. Int. 2009, 35, 3117-3124. [CrossRef]

11. Stinnessen, I.; Buhr, A.; Kockegey-Lorenz, R.; Racher, R. High Purity Calcium Aluminate Cements, Production and Properties; Alcoa World Chemicals: Franfurt, Germany, 2001.

12. Kumar, V.; Singh, V.K.; Srivastava, A.; Hemanth Kumar, P. Mechanochemically synthesized high alumina cement and their implementation as low cement castables with some micro-fine additives. J. Asian Ceram. Soc. 2018, 3, 92-102. [CrossRef]

13. Sako, E.Y.; Braulio, M.A.L.; Milanez, D.H.; Brant, P.O.; Pandolfelli, V.C. Microsilica role in the CA6 formation in cement-bonded spinel refractory castables. J. Mater. Process. Technol. 2009, 209, 5552-5557. [CrossRef]

14. Saltzberg, M.A.; Bors, S.L.; Bergna, H.; Winchester, S.C. Synthesis of chemically stabilized cristobalite. J. Am. Ceram. Soc. 1992, 75, 89-95. [CrossRef]

15. An, J.; Wang, Y.; Jia, Q.; Zhao, F.; Liu, X. Microstructure and reactivity evolution of colloidal silica binder in different systems at elevated temperatures. Ceram. Int. 2020, 46, 20129-20137. [CrossRef]

16. Ismael, M.; Salomão, R.; Pandolfelli, V. Refractory castables based on colloidal silica and hydratable alumina. Am. Ceram. Soc. Bull. 2007, 86, 58.

17. Wang, F.; Chen, P.; Li, X.; Zhu, B. Effect of Colloidal Silica on the Hydration Behavior of Calcium Aluminate Cement. Materials 2018, 11, 1849. [CrossRef]

18. Ismael, M.; Anjos, R.d.; Salomão, R.; Pandolfelli, V. Colloidal silica as a nanostructured binder for refractory castables. Refract. Appl. News 2006, 11, 16-20.

19. Lv, X.; Ye, F.; Cheng, L.; Fan, S.; Liu, Y. Binder jetting of ceramics: Powders, binders, printing parameters, equipment, and post-treatment. Ceram. Int. 2019, 45, 12609-12624. [CrossRef]

20. Mostafaei, A.; Elliott, A.M.; Barnes, J.E.; Li, F.; Tan, W.; Cramer, C.L.; Nandwana, P.; Chmielus, M. Binder jet 3D printing-Process parameters, materials, properties, modeling, and challenges. Prog. Mater. Sci. 2021, 119, 100707. [CrossRef]

21. Subramanian, A.S.; Peng, E.; Lau, W.C.; Goh, D.C.W.; Pramono, S.; Sriramulu, D.; Wu, Y.; Kobayashi, H.; Moo, J.G.S.; Su, P.-C. Morphological Effects of Various Silica Nanostructures on the Mechanical Properties of Printed Parts in Digital Light Projection 3D Printing. ACS Appl. Nano Mater. 2021, 4, 4522-4531. [CrossRef]

22. Anwar, N.; Sappinen, T.; Jalava, K.; Orkas, J. Comparative experimental study of sand and binder for flowability and casting mold quality. Adv. Powder Technol. 2021, 32, 1902-1910. [CrossRef]

23. Hodbe, G.; Shinde, B. Design and Simulation of Lm 25 sand casting for defect minimization. Mater. Today Proc. 2018, 5, $4489-4497$. [CrossRef] 